\title{
Vector control Aedes sp. during pandemic COVID-19
}

\author{
Nur Alvira Pascawati ${ }^{1}$, Eka Silvia Saputri ${ }^{2}$, Fajarina Lathu ${ }^{3}$, Rizky Erwanto ${ }^{4}$, Venny Vidayanti ${ }^{5}$ \\ ${ }^{1}$ Public Health Study Program, Faculty of Health Science, Respati University of Yogyakarta, Yogyakarta, Indonesia \\ $2,3,4,5$ Nursing Study Program, Faculty of Health Science, Respati University of Yogyakarta, Yogyakarta, Indonesia
}

\begin{tabular}{|c|c|}
\hline Article Info & ABSTRACT \\
\hline Article history: & \multirow{11}{*}{$\begin{array}{l}\text { During the coronavirus disease } 2019 \text { (COVID-19) outbreak in Indonesia, the } \\
\text { government also faces another health problem, namely dengue hemorrhagic } \\
\text { fever (DHF). The routine activities of the dengue management system have } \\
\text { been significantly curtailed as government authorities concentrate more on } \\
\text { containing the transmission of the COVID-19. This study aimed to describe } \\
\text { vector control Aedes sp. during pandemic COVID-19, such as community } \\
\text { activities in controlling breeding places, area risk, vector density and the } \\
\text { determinant factors. This study was a community-based cross-sectional } \\
\text { survey involving } 136 \text { households in the endemic area of Gondokusuman } \\
\text { District, Yogyakarta, Indonesia using proportionate stratified random } \\
\text { sampling. Data analysis was performed through simple and multiple logistic } \\
\text { regression tests. Vector control for Aedes sp. breeding places during } \\
\text { pandemic COVID-19 in the community are still low; the high level of vector } \\
\text { density proves this based on House Index (HI): } 44.1 \% \text {, container index (CI): } \\
57.4 \% \text {, and Breteau Index (BI): } 213.2 \% \text {. This district is also at high risk to be } \\
\text { the breeding places of Aedes sp. based on maya index (MI): } 64.7 \% \text {. The } \\
\text { determinant factor that affects this condition is the lack of support by health } \\
\text { workers/cadres during the COVID-19 pandemic. }\end{array}$} \\
\hline Received Mar 2, 2021 & \\
\hline Revised Aug 6, 2021 & \\
\hline Accepted Aug 21, 2021 & \\
\hline Keywords: & \\
\hline Aedes sp. & \\
\hline COVID-19 & \\
\hline Health workers support & \\
\hline Maya index & \\
\hline Vector density & \\
\hline & \\
\hline
\end{tabular}

This is an open access article under the CC BY-SA license.

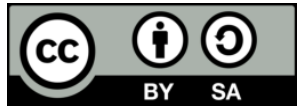

\section{Corresponding Author:}

Nur Alvira Pascawati

Public Health Study Program

Faculty of Health Science

Respati University of Yogyakarta, Yogyakarta, Indonesia

Email: alvirapascawati@respati.ac.id/irha011185@yahoo.com

\section{INTRODUCTION}

Dengue is one of the infections of four dengue virus (DENV) stereotypes (1-4) transmitted by mosquitos [1], [2]. The clinical manifestation of DENV infections is ranged from asymptomatic infections or mild flu-like syndromes known as dengue fever (DF) to more severe and life-threatening symptoms, namely dengue hemorrhagic fever (DHF), and dengue shock syndrome (DSS) [3]. It is estimated that there are 390 million people infected by DENV every year all over the world [4], in which 50-200 million are real cases (symptomatic infections, including those undetected by the reporting system) [4], [5]. Data from 76 countries show substantial increases in dengue fever incidents, in which the number of cases doubled and more every decade between 1990 and 2013, with the highest infection incidents reported in Asian countries [5].

Indonesia is one of the countries in Asia ranked first of DHF cases during 1990-2015 based on incidence rate (IR) and case fatality rate (CFR) [4], [6], [7]. When the Coronavirus Disease 2019 (COVID19) pandemic is still happening in Indonesia, the government also faces another health issue: DHF. The high, increasing number of COVID-19 cases caused Indonesia to be ranked $19^{\text {th }}$ globally, and $4^{\text {th }}$ in Asia, and $1^{\text {st }}$ in Southeast Asia on January 17, 2021 [8], [9]. The concerning number of COVID-19 cases is in line with the high number of cases and deaths of DHF in Indonesia. The DHF cases in 2020 until the week 49 were 95,893 
people, while the number of deaths has reached 661 people. About $73.35 \%$ or 377 regencies/municipalities almost reached 49/100,000 population of IR [10], [11]. A previous study in Indonesia has predicted that the number of dengue cases during the COVID-19 Pandemic for 12 months in 2020 is expected to remain high throughout the year [12]. Yogyakarta Special Region, Indonesia is one of the regions included in Indonesia's four highest cases during 2015, and Yogyakarta City is the part of DIY region with the highest IR during 2016-2017. In 2019, the IR was above the national average, namely 115/100,000 population [13].

Various preventive measures for DHF have been done in Indonesia, one of which is through the vector control by Mosquito Nest Eradication (MNE) that became the purpose of community-based control program [14]. This program shows significant results in decreasing DHF incidents in some countries because they have a high awareness of the vector [14], [15]. However, the increased cases of COVID-19 in Indonesia have given pressures to the program because the system implemented to monitor the mosquito breeding places, either independently by the people or conducted by the government, cannot be done maximally [16]. Large-scale social restrictions (LSSR) to prevent the transmission of COVID-19 cause's health workers to focus on the controlling measures of COVID-19 restricts movements of health workers when coordinating with health cadres, affects in minimum efforts of cadres to motivate and monitor people in conducting MNE through vector survey activities. LSSR also makes it impossible for people to mutually cooperate in cleaning the mosquito breeding places within their environment [11]. Previous study conducted in Malaysia showed that there was an outbreak of new DHF cases in all regions during movement control order (MCO) phase III. The infection rate and transmission of DHF surpass COVID-19 transmission's rate at that time [17].

There is a lack of evidence in Indonesia that describes the potential factors for the failure of DHF control programs in the community explicitly, particularly when large-scale social restrictions are implemented during COVID-19 Pandemic. This study aimed to describe community activities in controlling breeding places of Aedes sp., area risk levels, vector density and the determinant factor during the COVID-19 pandemic in Yogyakarta Province, Indonesia. The results of this study could bring a significant contribution for decision-makers in formulating practical steps to control the spread of dengue during the COVID-19 pandemic or other disease outbreaks, which might cause community-based failure DHF preventive measure program.

\section{RESEARCH METHOD}

\subsection{Data collection}

This study was a cross-sectional community-based survey [18]. The study was conducted in the Gondokusuman District of Yogyakarta City, Indonesia namely the area with a high endemic category and ranked third in the increasing number of DHF cases during 2019 and 2020. This study's population was the entire households in the research location in which the sample was calculated through a two-proportion sample formula (2-tailed test) [19], which resulted in 136 households. The sample was collected through a proportionate stratified random sampling. In this study, the number of samples was taken in five villages in Gondokusuman District, and the number of samples was based on the total population in each village. The sampling technique in each village was carried out randomly. Furthermore, due to the COVID-19 pandemic, there were three inclusion criteria: the wife or husband in one household, neighbourhood led or hamlet that is not in the lockdown status due to COVID-19 pandemic and no family members who conduct self-isolation or quarantine.

\subsection{Ethical approval}

This study has been approved by the Commission of Ethics of Faculty of Health Science, Respati University of Yogyakarta, with Protocol Number: 133.3/FIKES/PL/VII/2020 on July 2020.

\subsection{Study instrument}

Research variables consisted of dependent variables: knowledge and attitude regarding the threats of DHF, DFH illness history of family members, the social activity (mutual cooperation) restrictions for family members, and the support of health workers/cadres in performing DHF preventive measures during the COVID-19 pandemic. The validity test of the instrument (knowledge, attitude, social activity and support of health workers/cadres) used the construct method on 30 households at the research location. The test results on valid items were directly used as research questions. The test results with correlation product-moment showed that 41 items had r-count $0.465-0.867>\mathrm{r}$ table: 0.361 , meaning that the question was declared valid. The value of the reliability coefficient using the Cronbach's Alpha test shows r-count: $0.828>0.8$ indicating a strong reliability value. The DHF preventive measures through the control of breeding places of vector Aedes sp. were based on the physical measure (Draining, Covering, Burying or Reusing), chemical measure (larviciding), biological measure (using larva-eating fishes). Variables are validated through direct 
observations conducted by the researcher in all container in reference to the guideline from the Ministry of Health [20].

Knowledge was classified into three categories, namely good: if the score is $>80 \%$, medium if the score is $60-80 \%$, and low if the score is $<60 \%$ [21]. The attitude was classified into positive if the $\mathrm{T}$ score is $\geq 50 \%$ and negative if the $\mathrm{T}$ score is $<50 \%$. The support of health workers/cadres during the COVID-19 pandemic was classified into two categories: contributing properly/present if the score is $\geq 50 \%$ and contributing poorly/absent if the score is $<50 \%$ [22]. The social activity (mutual cooperation) restrictions for family members were classified into two: good, if the family members are allowed to conduct mutual cooperation by applying strict medical protocols, and poor, if family members are not allowed to perform mutual cooperation during the pandemic. DHF illness history is if a family member had DHF in the past year based on the report of Epidemiological Investigations of Community Health Centre and the Early Warning System Scores used by the hospital [23]. DHF preventive measures are the behaviours of family members in preventing the breeding places of vector Aedes sp. through physical, chemical, and biological measures proven by the discovery or non-discovery of Aedes sp. larvae on the containers examined inside and outside the houses with the inspection range adjusted to the area owned by the house owners [22].

The observation results of the presence of larvae in containers were measured by using the indicators of container index $(\mathrm{CI})$, house index $(\mathrm{HI})$, breteau index $(\mathrm{BI})$, and maya index $(\mathrm{MI})$. CI is acquired by dividing the number of larva-positive containers with the number of examined containers multiplied by $100 \%$. HI is acquired by dividing the number of larva-positive houses with the number of examined houses multiplied by $100 \%$. BI is obtained by dividing the number of larva-positive containers with the number of examined houses multiplied by $100 \%$ [24]. MI is one of the quantitative approaches applied to identify the risk of an area used as a breeding site by Aedes mosquitos based on environmental health status. MI uses two indices: The hygiene risk index (HRI) and breeding risk index (BRI). HRI is obtained by counting the availability of disposable containers (DC), namely water reservoirs (TPA), no longer used or had become waste. At the same time, BRI is acquired by counting the availability of Controllable Containers (CC), namely water reservoirs (TPA) that still be used for specific purposes. BRI is measured by dividing the number of $\mathrm{CC}$ found in the cemetery divided with the average larva-positive $\mathrm{CC}$. HRI is the result of dividing the number of DC in the cemetery by the average larva-positive DC. Both indices are categorized into three categories: high, medium, and low based on tertile distribution [25], [26]

\subsection{Statistical analysis}

Data were analyzed through three stages, namely univariate analysis: data were presented in the frequency distribution, percentage, and proportion, to picture people's action in conducting control measures for vector Aedes sp. breeding places, area risk levels, and vector density. Bivariate and multivariate analyses applied simple and multiple logistic regression tests with $\alpha=0.05$. The results of simple logistic regression analysis were used to determine variables related to control measures for vector Aedes sp. breeding places and select variables suitable as the model of appropriate control measures during the COVID-19 pandemic with p-value <0.25 [27]. The analysis was continued with multiple logistic regression tests through a backward method to discover the determinant variables related to DHF preventive measures in society during the COVID-19 pandemic. The assessment of model quality was performed to determine the discriminant value based on area under curve (AUC) through the receiver operating curve (ROC) method, while the model calibration used Hosmer and Lemeshow [28].

\section{RESULTS AND DISCUSSION}

\subsection{The description of respondent characteristics and control measures for vector Aedes sp. breeding} places

The majority of people in Gondokusuman District based on gender characteristic are female $(51.22 \%)$, while male amounted to $48.78 \%$. Most people are High School graduates that amounted to $28.67 \%$, while other educations are quite varied, namely, junior high school graduates, elementary school graduates, and Diploma/Bachelor/Equivalent. The assessment results of education level and attitude regarding the threats of DHF, the social activity (mutual cooperation) restrictions for family members, the support of health workers/cadres, and control measures for vector Aedes sp. breeding places during the COVID-19 pandemic in Yogyakarta City as shown in Table 1. 
Table 1. The description of control measures for vector Aedes sp. breeding places during the COVID-19 pandemic of people in Yogyakarta City

\begin{tabular}{|c|c|c|}
\hline Variables & Frequency & Percentage $(\%)$ \\
\hline \multicolumn{3}{|l|}{ The knowledge about DHF's threats } \\
\hline -Good & 84 & 61.8 \\
\hline -Fair & 35 & 25.7 \\
\hline -Lacking & 17 & 12.5 \\
\hline \multicolumn{3}{|l|}{ The attitude towards DHF's threats } \\
\hline -Positive & 105 & 77.2 \\
\hline -Negative & 31 & 22.8 \\
\hline \multicolumn{3}{|l|}{ DHF illness history } \\
\hline -Sick & 20 & 14.7 \\
\hline -Not sick & 116 & 85.3 \\
\hline \multicolumn{3}{|l|}{ Social activity (mutual cooperation) restrictions for family } \\
\hline $\begin{array}{l}\text {-Exist } \\
\text { - Not exist }\end{array}$ & 56 & 41.2 \\
\hline \multicolumn{3}{|l|}{ The support of health workers/cadres } \\
\hline -Contribute properly & 93 & 68.2 \\
\hline -Contribute poorly & 43 & 31.8 \\
\hline \multicolumn{3}{|l|}{ Preventive measures } \\
\hline - Conducting physical activities (Draining, Covering, & 76 & 55.9 \\
\hline Burying/Reusing) & 32 & 23.5 \\
\hline $\begin{array}{l}\text { - Conducting chemical activities (Larviciding) } \\
\text { - Conducting biological activities (Fish/Shrimp) }\end{array}$ & 16 & 11,8 \\
\hline
\end{tabular}

Table 1 show that most people have adequate knowledge and positive attitudes towards DHF's threats. There are $20(14.7 \%)$ households with the DHF illness history on their family members in the past year based on the epidemiological investigations (PE) and the Early Warning System Scores used by the hospital. During the COVID-19 pandemic, most family heads restrict the activity of their family members in doing the mutual cooperation in their neighborhood areas, such as cemetery, neighborhood watch post(s), empty land(s), and uninhabited houses. Most health workers and cadres' still support family heads to conduct control measures for vector Aedes sp. breeding places. During the COVID-19 pandemic, health workers and cadres do not perform home visits; therefore, the support is carried out by sending messages through the Whatsapp group. The physical control measures for vector breeding places undertaken by family members are draining, covering, and burying used goods; therefore, no Aedes sp. larvae were found in $55.9 \%$ of households. The chemical control measure by disseminating larvicides on big containers used to contain a large amount of water in a very long time, such as water reservoirs, was only carried out by $23.5 \%$ of households. The biological measure by disseminating larva-eating fishes/shrimps on containers, such as wells, used fish ponds, and big flower pots, was only done by $11.8 \%$ of households.

\subsection{The density levels of Aedes sp. larvae}

The density levels based on the indicators of container index (CI), house index (HI), and breteau index $(\mathrm{BI})$ can be seen in Table 2.

Table 2. The larvae density levels during the COVID-19 pandemic in Yogyakarta City

\begin{tabular}{ccccccc}
\hline \multicolumn{2}{c}{ Number } & \multicolumn{2}{c}{ Larva-positive } & HI (\%) & CI (\%) & BI (\%) \\
House & Container & House & Container & & & \\
\hline 136 & 505 & 60 & 290 & 44.1 & 57.4 & 213.2 \\
\hline
\end{tabular}

The observation results of larvae existence on 136 houses and 505 containers can potentially become the Aedes sp. larvae breeding places during the COVID-19 pandemic based on HI, CI and BI. Physical, chemical, and biological control measures for vector Aedes sp. breeding places in the community during the COVID-19 pandemic are deficient. This condition can be proved with the level of larvae density measured through container index (CI) and breteau index (BI) indicators, which resulted in the scale of nine or the high category based on WHO's Density Figures, in addition, house index (HI) shows the scale of six or high category [24]. These results show that the spreading of vector Aedes $s p$. in the community environment is very high, and the vector-controlling program does not run optimally during the COVID-19 pandemic. 


\subsection{Area risk levels based on maya index}

The characteristics of containers found in the neighbourhood and would potentially become the breeding places of vector Aedes sp. during the COVID-19 pandemic based on maya index (MI) are divided into two, namely controllable containers (CC) and disposable containers (DC), with details shown as follows. Table 3 shows that most containers used in the neighbourhood are 328 controllable containers (CC) and 177 disposable containers (DC), however, it is found that DC-type containers are the most larva-positive. CCtype container that the people mostly use is water tub, but the container found with the most larvae is the dispenser water tank. The DC-type container found most in the neighbourhood and determined as larvapositive is used plastic glass. The classification results of the two container types are used to measure the risk level in the neighbourhood during the COVID-19 pandemic based on the hygiene status through the value of hygiene risk index (HRI) and the existence of breeding places of mosquitos through the breeding risk index (BRI) as shown in Table 3.

Table 3. The characteristics of people's containers during the COVID-19 pandemic in Yogyakarta City

\begin{tabular}{lcccc}
\hline \multicolumn{1}{c}{ Types of containers } & Number & Container with larvae & \% Larva-positive & \% Larva-positive of the total container \\
\hline Controllable containers (CC) & 328 & 139 & 42.4 & 47.9 \\
Water tub & 70 & 38 & 54.3 & 13.1 \\
Crock & 87 & 24 & 27.6 & 8.3 \\
Water tank dispenser & 35 & 26 & 74.3 & 9.0 \\
Flower vase & 1 & 0 & 0.0 & 0.0 \\
Refrigerator water tank & 22 & 15 & 68.2 & 5.2 \\
Gutter & 4 & 2 & 50.0 & 0.7 \\
Flower pot & 67 & 26 & 38.8 & 9.0 \\
Bucket & 15 & 2 & 13.3 & 0.7 \\
Well & 5 & 3 & 60.0 & 1.0 \\
Ponds & 4 & 3 & 75.0 & 1.0 \\
Bird drinking container & 16 & 0 & 0.0 & 0.0 \\
Aquarium & 2 & 0 & 0.0 & 0.0 \\
Disposable containers (DC) & 177 & 151 & 85.3 & 52.1 \\
Used tire & 23 & 20 & 87.0 & 6.0 \\
Used can & 49 & 44 & 89.8 & 15.2 \\
Used plastic glass & 66 & 62 & 93.9 & 21.4 \\
Used bucket & 6 & 5 & 83.3 & 1.7 \\
Tree hole & 25 & 17 & 68.0 & 5.9 \\
Others & 8 & 3 & 37.5 & 1.0 \\
Total & 505 & 290 & & 100 \\
\hline
\end{tabular}

Table 4 shows that most of the community environment is categorized as unclean based on HRI values; therefore, they have a high risk of becoming vector Aedes sp. breeding places due to lots of larvapositive DC found. The community environment is categorized as medium risk based on the BRI values because the people still have lots of CC that potentially become mosquito breeding places. However, the existence of larvae can still be controlled compared to the discovery of larvae in DS. Table 5 shows that most houses are in the high category during the COVID-19 pandemic based on the category of MI that might become the vector Aedes sp. breeding places, thus they potentially get transmitted by DHF. Based on the maya index (MI) indicator, the community environment is at a high risk of becoming the potential breeding places of vector Aedes sp. during the COVID-19 pandemic. This score was based on a high Hygiene Risk Index (HRI), which means that the environment is unclean because many waste/DC were found. The breeding risk index (BRI) showed a medium score because the people still have goods like $\mathrm{CC}$ that can potentially become breeding places of mosquitos.

Table 4. 3x3 Matrix of BRI, HRI, and MI value proportion during the COVID-19 pandemic in Yogyakarta

\begin{tabular}{clcccccc}
\multicolumn{4}{c}{ City } \\
\hline \multirow{2}{*}{ HRI/BRI categories } & \multicolumn{4}{c}{ Low } & \multicolumn{2}{c}{ Medium } & \multicolumn{2}{c}{ High } \\
& & $\mathrm{n}$ & $\%$ & $\mathrm{n}$ & $\%$ & $\mathrm{n}$ & $\%$ \\
\hline \multirow{3}{*}{ HRI } & Low & 2 & 1.5 & 8 & 5.9 & 11 & 8.1 \\
& Medium & 12 & 8.8 & 22 & 16.2 & 21 & 15.4 \\
& High & 17 & 12.5 & 67 & 49.3 & 43 & 31.6 \\
\hline
\end{tabular}

Note: green= low risk; yellow= medium risk; red= high risk 
Table 5. The value proportion of BRI, HRI, and MI during the COVID-19 pandemic in Yogyakarta City

\begin{tabular}{lcccccc}
\hline \multirow{2}{*}{ Categories } & \multicolumn{2}{c}{ HRI } & \multicolumn{2}{c}{ BRI } & \multicolumn{2}{c}{ Maya Index } \\
& $\mathrm{n}$ & $\%$ & $\mathrm{n}$ & $\%$ & $\mathrm{n}$ & $\%$ \\
\hline Low & 13 & 9.6 & 19 & 14.0 & 12 & 8.8 \\
Medium & 42 & 30.9 & 69 & 50.7 & 36 & 26.5 \\
High & 81 & 96.9 & 48 & 35.3 & 88 & 64.7 \\
Total & 136 & 100.0 & 136 & 100.0 & 136 & 100.0 \\
\hline
\end{tabular}

The pre-adult growth of vector Aedes sp. is highly determined by the availability of water, water container, and environment (rainfall and season) [29]. Aedes has a great adaptation to various environmental conditions by utilizing puddles on open containers as the breeding site [30]. The high value of HRI showed that the community puts a minimum concern on the hygiene of the environment around their residence, especially during the rainy season that can potentially cause water puddles on used containers outside the houses. ost of the visited houses have a high risk of DHF transmission. Many potential containers found positive with Aedes sp., both inside and outside the houses; therefore, this condition can be the main factor of DHF transmission because one of the dengue viruses does not only transmit horizontally but can also be transmitted vertically between generations of the Aedes sp. mosquito to its offspring (transovarial transmission) [31]. This finding is different from the results of some previous studies on the maya index before the COVID-19 pandemic, which showed that some areas have a medium risk [32], [33].

\subsection{Factors associated with the control measures for vector Aedes sp. breeding places}

Factors associated with control measures for vector Aedes sp. breeding places during the COVID-19 pandemic in the society can be seen in Table 6 . Table 6 demonstrates that sufficient public knowledge about the threats of DHF has a risk of 1.0909 times towards the low control measures for vector Aedes $s p$. breeding places; however, statistically, there is no significant difference with the group with good knowledge and has better control measures. The community's insufficient knowledge regarding DHF's threats has a risk of 1.7968 times toward the low control measures for vector Aedes sp. breeding places. This magnitude is substantiated by the statistical test results, which showed a significant difference compared to the group with good knowledge and control measures. The community's negative attitude regarding DHF's threats has a risk of 2.2581 times toward the low control measures for vector Aedes sp. breeding places. This magnitude is substantiated by the statistical test results that showed a significant difference compared to the group with positive attitudes and better control measures.

Table 6. Factors associated with the control measures for vector Aedes sp. breeding places during the COVID-19 pandemic of the people in Yogyakarta City

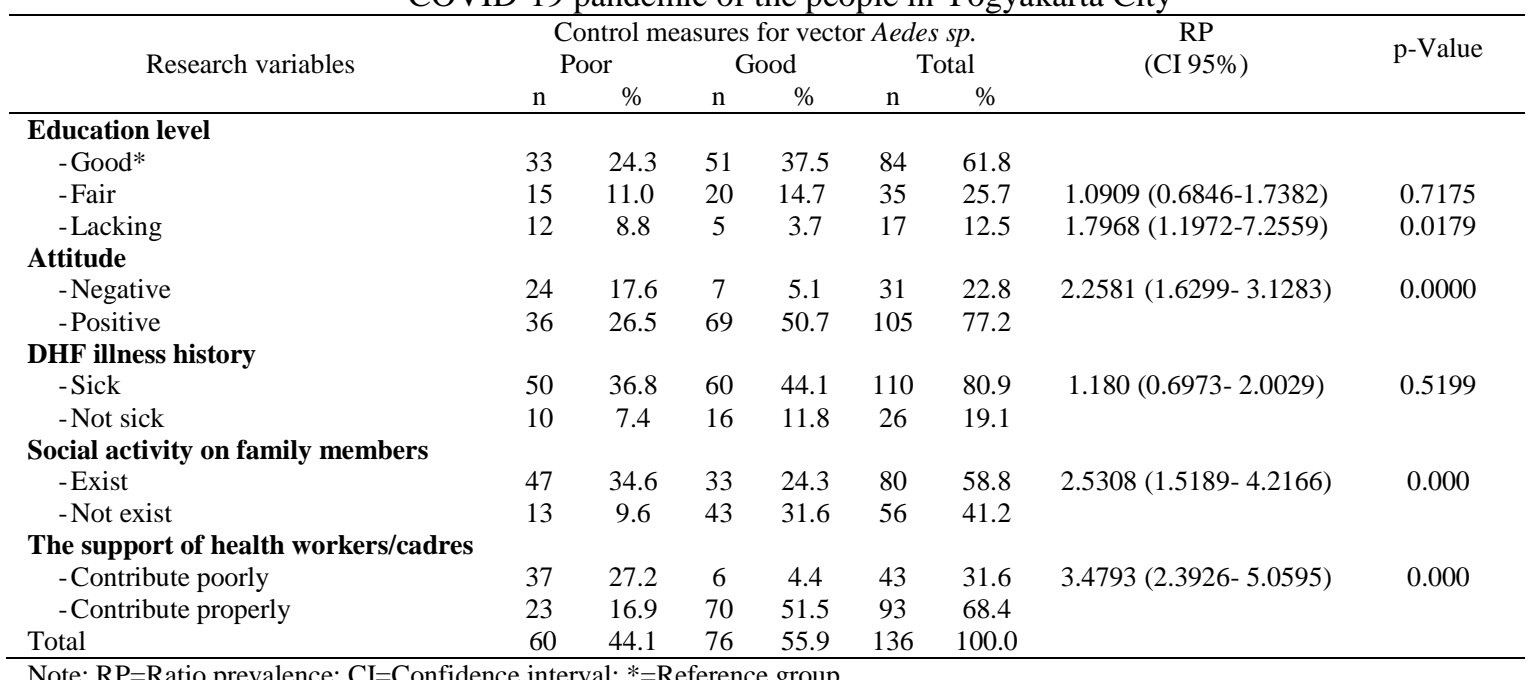

Note: $\mathrm{RP}=$ Ratio prevalence; $\mathrm{CI}=$ Confidence interval; *=Reference group

Most people have good knowledge and a positive attitude regarding the DHF's threats. This condition is caused by the socialization activities conducted by Community Health Centre to the community before the COVID-19 pandemic that was done routinely. The socialization and education program is the priority program of Gondokusuman Community Health Centre because this area has a high-endemic status 
and $<95 \%$ of larva-free index [13]. It has been found that some family heads have sufficient knowledge, even lacking, and negative attitudes towards DHF's threats. This condition shows that some family heads consider DHF's threats lightly because socialization activities have not given adequate, and not all of the community has participated in the activities. The lack of knowledge and negative attitudes regarding DHF's threats might affect preventive measures done by the community because knowledge or cognition is a crucial domain for one's action [34]. Negative attitudes indicate the unpreparedness of the community in conducting preventive measures because attitudes have a directed impact on one's activity [35]. These research results are similar to the study done in the Bangladesh and Ethopia, which showed that relationship between knowledge and preventive measures for DHF's threats was also found in these two country [36], [37]. Based on the description of people's attitude towards DHF's threats, these research results are still better than the research results in Mataram City and Nepal. It is also known that there was a relationship between the people's attitude with the preventive measures of DHF [22], [38].

Most samples in this study did not have an illness history of DHF in the past year; however, this area is categorized as endemic and had experienced an outbreak of DHF. Several studies have indicated that if a family member had suffered from DHF, there would be a lesson learned on a better anticipative attitude to conduct the prevention [39], [40]. Research results show that the illness history of DHF is not related to control measures of vector Aedes sp. breeding places during the COVID-19 pandemic. This condition is consistent with other studies that indicate that the information received when a family member suffers from DHF through health educational activities can improve the awareness regarding the dengue infection but might not be sufficient to maintain larvae's control practice [41]. While this area is determined as DHF endemic, the health socialization activities regarding the prevention of DHF conducted in the neighbourhood are not necessarily followed by all local people. Several studies have shown that adequate socialization faces many challenges, such as cost-benefit and people mobility [42]. Therefore, health authorities should consider prioritizing the local people in designing the socialization activity of DHF's prevention to encourage the community participation level.

Family heads restrict their family members' social activities during the COVID-19 pandemic by prohibiting them from cleaning public facilities close to the houses, such as a cemetery, school, empty land(s), neighbourhood watch post and uninhabited dwellings. This prohibition is due to the concern regarding the transmission of COVID-19 during the activity. Aedes sp. mosquitoes' behaviour that sucks blood during 08:00-17:00 will occur more frequently in the morning compared to the afternoon, with a low prevalence between 13:00-14:00 [43]. These hours are in line with outdoor human activities, including working, go to school, and running other social activities. Since the COVID-19 pandemic in Indonesia, the government implements large-scale social restrictions (LSSR) and lockdown status in some villages [44]. This study shows that social activity restrictions in the community resulted in low control measures of vector Aedes sp. breeding places. The local people cannot conduct the eradication of mosquito nests massively through priority programs, such as mutual cooperation, collective actions in eradicating mosquito nests, and house-to-house vector survey by larva-monitoring cadres [13]. The LSSR also cause most family heads forbid their family members to cleaning public facilities close to the house: cemetery, school, empty land(s), and uninhabited houses. This condition is proven by many Aedes sp. larvae found in used goods compared to the containers that still be used for daily needs. This condition is made worse by the overloaded landfills in Yogyakarta City, so the waste collection in the community by the janitors must be stopped for a couple of weeks [45], [46].

The support of health workers for every community member to routinely perform control measures of vector Aedes $s p$. breeding places during the COVID-19 pandemic does not run optimally. The LSSR cause the preventive and control measures of DHF to be restricted in which the control of dengue vector and indoor spraying with household pesticide products are only be done by the resident [47]. The restriction of activities between the local people and health cadres in the neighborhood is due to the concern of there would be a gathering, not keeping a distance, not wearing a mask during activities, and not washing hands directly after the activities. The government tries maximally to decrease the number of COVID-19 cases in Yogyakarta City, so the entire health workers are focused on testing, tracing, and treatment activities [48]. Therefore, the frequency of educational activity, socialization, and DHF vector surveillance in the community decrease. Before the COVID-19 pandemic, the educational, socialization and vector surveillance activities in the endemic areas of DHF were conducted through routine meetings. However, these activities must be stopped during the pandemic and be replaced with communication and education through online media, such as Whatsapp. The use of online communication media cannot be reached entirely by all layers of society because not all of them own smartphone, laptop, capable of purchasing internet package, and capable of using electronic devices. 


\subsection{Determinant factors related to control measures for vector Aedes $s p$. breeding places}

The multivariate analysis was performed to discover determinant factors affecting control measures of vector Aedes sp. breeding places during the COVID-19 pandemic of the people in Yogyakarta City, Indonesia. There were four variables selected in the bivariate analysis due to p-value $<0.25$ and considering the contributing variables toward control measures of vector Aedes sp. breeding places during the COVID-19 pandemic in Yogyakarta City. These variables were: lack of knowledge regarding the DHF's threats, negative attitudes on DHF's threats, the social activity (mutual cooperation) restrictions on family members, and the lack of contribution of health workers/cadres in carrying out the monitoring, counselling, and giving attention during the COVID-19 pandemic. Table 7 shows that the determinant factor related to control measures for vector Aedes sp. breeding places during the COVID-19 pandemic in the community environment of Yogyakarta City is the decreasing support of health workers/cadres $(\operatorname{Exp} \beta=3.738)$. This factor is substantiated by the social activity (mutual cooperation) restrictions on family members $(\operatorname{Exp} \beta=3.340)$ and the negative attitude towards DHF's threats $(\operatorname{Exp} \beta=1.239)$. These are the probability and function results to predict the low control measures of vector Aedes sp. breeding places during the COVID-19 pandemic in the society.

Table 7. Determinant factors related to control measures for vector Aedes sp. during the COVID-19 pandemic of the people in Yogyakarta City

\begin{tabular}{lccccc}
\hline \multicolumn{1}{c}{ Variables } & \multirow{2}{*}{ Sig. } & \multirow{2}{*}{$\operatorname{Exp}(\beta)$} & $\begin{array}{c}\text { 95\% C.I.for Exp }(\beta) \\
\text { Lower }\end{array}$ & Upper \\
\hline The support of health workers/cadres & 2.314 & 0.000 & 3.738 & 1.239 & 7.946 \\
Social activity restrictions & 1.206 & 0.000 & 3.340 & 1.745 & 6.390 \\
Attitude & 1.008 & 0.012 & 2.741 & 1.137 & 6.606 \\
Education level & 0.971 & 0.069 & 1.239 & 0.901 & 5.639 \\
Constant & -4.658 & 0.000 & .073 & & \\
Note: $\operatorname{Exp}(\beta)=$ Exponent Beta; Sig.=Significance; Exp (B)=Exponent Beta
\end{tabular}

The result of the function quality assessment based on the calibration parameters of the Hosmer and Lemeshow Test showed 0.741 score, which means that the acquired function has a decent calibration because p-value $>0.05$. The discriminant value based on area under curve (AUC) was $0.723(72.3 \%=$ close to $100 \%)$. The discovered variables were categorized as robust that become the model fit in predicting control measures for vector Aedes sp. breeding places during the COVID-19 pandemic.

Function $(y)=-4.658+2.314($ The support of health workers/cadres $)+1.206$ (Social activity restrictions $)+1.008($ attitude $)+$ 0.971 (education level) $=0.841$

Probability $(\mathrm{P})=\frac{1}{\left(1+e^{-y}\right)}=\frac{1}{\left(1+2,7^{-0,841}\right)}=0.434 \times 100=69.75 \%$

Notes:

$\mathrm{P}=$ the probability of an event occurring

$\mathrm{e}=$ natural number $=2.7$

$\mathrm{y}=$ Constant

These equations/functions show the lack of health workers/cadres' contributions, the restriction on family members' social activity (mutual cooperation), low education levels, and negative attitudes on DHF's threats contribute $69.75 \%$ on insufficient control measures of vector Aedes sp. breeding places during the COVID-19 pandemic of the people in Yogyakarta City.

The low control measures for vector Aedes sp. breeding places during the COVID-19 pandemic cause the high level of vector density and can potentially get transmitted by DHF. The determinant factor that causes this condition is the decreasing contribution of health workers/cadres. This factor is substantiated with the social activity (mutual cooperation) restrictions on family members, negative attitudes, and lack of knowledge regarding DHF's threats. The role of health cadres can be optimized to mobilize the community in running the Mosquito Nest Eradication activities because the presences of cadres as the part of local figures are more known in their environment. They have the power to make people aware and guide the community in carrying out DHF preventive measures. There are research results that have shown the success of Routine Larva Monitoring in improving the Larva-Free Rate due to the support of health cadres [49]-[52]. The role of health workers and cadres can be shown by motivation, coordination, and policy implementation [53], [54], including giving direct encouragements towards the community to do more personal steps in monitoring the existence of larvae in every container inside and outside the houses. This can be done through routine meetings to discuss the DHF preventive plans.

During the COVID-19 pandemic, the government has asked the community to get ready with the new normal adaptation (NNA). The NNA means that the community can return to their activities but with 
some restrictions and implement a discipline health protocol [55]. This new normal adaptation can be the measure to suppress the risk of DHF transmission through Mosquito Nest Eradication (MNE) activities that can be done independently, collectively, or cooperatively with the government. Health workers helped with cadres can start to drive the community to make a schedule and division of workgroups routinely for at least once a week to clean the surrounding environment that can potentially be vector breeding places. The implementation of such activities should still be based on the Regional Regulation of Yogyakarta Special Region concerning the control of COVID-19 transmission [56]. Implementing the collective Mosquito Nest Eradication can be done by limiting the number of individuals involved, maintaining their distance during the activities, wearing the mask, preparing the facility to wash hands and obligating the people on duty to wash their hands before and after the activities. The health authorities should also design a better educational method and socialization concerning the DHF's threats during the COVID-19 pandemic, considering that not all people can access the information via online media. For that, the health-related messages regarding DHF through direct media with local wisdom should be kept, such as installing billboards, distributing leaflets, and reminding the householders to perform MNE through a loudspeaker because these media are effective in delivering the information about COVID-19 in the neighborhood [57], [58]. Gradually, the Larva-Monitoring cadres can do vector surveys through home visits by implementing the health protocol [59], [60].

\section{CONCLUSION}

The control measures for vector Aedes sp. breeding places during the COVID-19 pandemic in the community is low. This is proven by a high vector density level based on CI, HI, and BI indicators. This area also has a high risk to become the vector Aedes sp. breeding places because the support of health workers/cadres does not run optimally during the COVID-19 pandemic. This factor is substantiated by the social activity (mutual cooperation) restrictions, negative attitudes, and lack of knowledge about DHF's threats. These factors contribute $69.75 \%$ to the low control measures for vector Aedes sp. breeding places during the COVID-19 pandemic within the community.

\section{ACKNOWLEDGEMENTS}

The authors express their gratitude towards the Head of Respati University of Yogyakarta and the Local Leader of Gondokusuman District for the permission and the health cadres for the assistance during the data collection on the field.

\section{REFERENCES}

[1] WHO, "Global Strategy for Dengue Prevention and Control 2012-2020," Geneva, 2012. [Online]. Availabe: https://apps.who.int/iris/handle/10665/75303.

[2] B. Anne, and L. Ake, "Dengue Viruses-an Overview," Infection Ecology \& Epidemiology, vol. 3, no. 19839, pp. 121, 2013, doi: 10.3402/iee.v3i0.19839.

[3] I.M.S. Utama et al., "Dengue Viral Infection in Indonesia: Epidemiology, Diagnostic Challenges, and Mutations from an Observational Cohort Study," Neglected Tropical Diseases, vol. 10, no. e0007785, pp. 1-19, 2019, doi: 10.1371/journal.pntd.0007785.

[4] S. Bhatt et al., "The Global Distribution and Burden of Dengue," Nature, vol. 496, no. 7446, pp. 504-507, 2013, doi: 10.1038/nature12060.

[5] J. D. Stanaway et al., "The Global Burden of Dengue: An Analysis from the Global Burden of Disease Study 2013," Lancet Infect. Dis., vol. 16, no. 6, pp. 712-723, 2016, doi: 10.1016/S1473-3099(16)00026-8.

[6] I. Ruberto, E. Marques, D. S. Burke, and W. G. Van Panhuis, "The Availability and Consistency of Dengue Surveillance Data Provided Online by the World Health Organization,” PLoS Negl. Trop. Dis., vol. 9, no. 4, pp. 110, 2015, doi: 10.1371/journal.pntd.0003511.

[7] W. Trapsilowati et al., "Entomological Indicators and Risk for Dengue Transmisson in Java Island Indonesia," Vektora., vol. 11, no. 2, pp 79-86, doi: 10.22435/vk.v11i2.1829.

[8] S. Fauziyah et al., "How should Indonesia consider its Neglected Tropical Disease in the Covid-19 era? Hopes and Challenges (Review)," Biomedical Reports., vol. 14, no. 6, pp. 1-10, 2021, doi: 10.3892/br.2021.1429.

[9] OCHA, "Situation Update Respaonse to Covid-19 in Indonesia as of 4 July 2021," United Nations, 2021, [Online]. Available: https://reliefweb.int/report/indonesia/situation-update-response-covid-19-indonesia-4-june-2021-enid.

[10] W. Diarsvitri, R. Budiarti, P. A. Nugraheni, M. F. Ilmawan, and V. Biutifasari., "Dengue Lurks During Coronavirus Disease-19 Pandemic in Indonesia: A Narrative Review," Journal of Medical Science, vol. 8, no. T1, pp 391-398, doi: 10.3889/oamjms.2020.5.

[11] Ministry of Health of the Republic of Indonesia, "Until July, Dengue Cases in Indonesia Reached 71 Thousand," Directorate of Prevention and Control of Vector and Zoonotic Infectious Diseases," 2020. [Online]. Available: https://www.kemkes.go.id/article/view/20070900004.

[12] T. Respati, W. Wanti, and R. D. Nindrea, "Dengue Cases Prediction in Kupang," Glob. Med. Heal. Commun., vol. 8, no. 3, pp. 219-225, 2020, doi: 10.29313/gmhc.v8i3.6727. 
[13] R.W. Wila, T.B.T. Satoto, and Mujiyanto, "Distribution of Dengue Haemorrhagic Fever Cases and Breeding Places of Aedes aegypti and Pupae Index in Endemic and Non Endemic Area of East Sumba District, East Nusa Tenggara Province," Health Research Bulletin, vol. 48, no. 3, pp. 147-156, 2020, doi: 10.22435/bpk.v48i3.2900.

[14] H. Lin et al., "Community Involvement in Dengue Outbreak Control: An Integrated Rigorous Intervention Strategy," PLoS Negl. Trop. Dis., vol. 10, no. 8, pp. 1-10, 2016, doi: 10.1371/journal.pntd.0004919.

[15] F. Ramadhani, R. Yudhastuti, and S. Widati, "Consciousness Stage Implementation of Mosquito Nest Eradication (MNE) of Dengue Haemorrhagic Fever (DHF)," Research Article, vol. 1, no. 3, pp. 178-184, 2017.

[16] OCHA, "Dengue Fever Cases Still on the Rise desp.ite Seasonal Change in Some Regions," United Nations 2020, https://reliefweb.int/report/indonesia/dengue-fever-cases-still-rise-despite-seasonal-change-some-regions.

[17] M. H. Rahim, N. C. Dom, S. N. S. Ismail, Z. A. Mulud, S. Abdullah, and B. Pradhan, "The Impact of Novel Coronavirus (2019-Ncov) Pandemic Movement Control Order (MCO) on Dengue Cases in Peninsular Malaysia," One Heal., vol. 12, no. 3, pp. 1-10, 2021, doi: 10.1016/j.onehlt.2021.100222.

[18] T. L. Jones, M. Baxter, and V. Khanduja, "A Quick Guide to Survey Research," Ann. R. Coll. Surg. Engl., vol. 95, no. 1, pp. 5-7, Jan. 2013, doi: 10.1308/003588413X13511609956372.

[19] J. Faber and L. F, Fonseca, "How Sample Size Influences Research Outcome," Dental Press Journal of Orthodontics, vol. 19, no. 4. pp. 27-29, 2014, doi: 10.1590/2176-9451.19.4.027-029.ebo.

[20] Minsitry of Health, "Dengue Hemorrhagic Fever Control Module," Directorate of Disease Prevention and Control, 2011.

[21] F. A. Siregar et al., "Social and Environmental Determinants of Dengue Infection Risk in North Sumatera Province, Indonesia," Asian J. Epidemiol., vol. 8, no. 2, pp. 23-35, 2015, doi: 10.3923/aje.2015.23.35.

[22] N. A. Pascawati et al., "Knowledge, Attitudes and Practices on Community with Dengue Haemorrhagic Fever in Mataram, West Nusa Tenggara,” BALABA J. Litbang Banjarnegara, vol. 16, no. 2, pp. 149-158, 2020, doi: 10.22435/blb.v16i2.3165.

[23] N. P. Dewi and M. Azam, "Factors associated with the Mosquito Eradication Practice of DHF at Mulyoharjo Village,” Public Heal. Perpective J., vol. 2, no. 1, pp. 80-88, 2017, doi: 10.1371/journal.pone.0002620.

[24] T. B. T. Satoto et al., "Entomological Index and Home Environment Contribution to Dengue Hemorrhagic Fever in Mataram City, Indonesia," Kesmas Natl. Public Heal. J., vol. 15, no. 1, pp. 32-39, 2020, doi: 10.21109/kesmas.v15i1.3294.

[25] A. B. B. Wilke et al., "Cemeteries in Miami-Dade County, Florida are Important Areas to be Targeted in Mosquito Management and Control Efforts," PLoS One, vol. 15, no. 3, pp. 1-12, 2020, doi: 10.1371/journal.pone.0230748.

[26] T.W. Pertiwi., A E. Wikurendra, R. Yudhastuti, and A. Mirasa, "Preventive Behavior towards Maya Index at DHF Endemic Area," Enviroment Health, vol. 13, no. 1, pp. 1-8, 2021, doi: 10.20473/jkl.v13i1.2021.1-8.

[27] M. B. Suleiman, Z. B. B. Ibrahim, and A. F. N. B. Rasedee, "Solution of Higher-Order ODEs Using Backward Difference Method," Mathematical Problems in Engineering, vol. 2011, pp. 1-18, 2011, doi: 10.1155/2011/810324.

[28] Y. Yulianto, N. Robihaningrum, and B. D. Elinda, "Management Multivariate Analysis Methods for Variables Measurement in Scientific Papers," ATM, vol. 3, no. 1, pp. 65-72, 2019, doi.org/10.33050/atm.v3i1.826.

[29] R. Daswito and K. Samosir, "Physical Environments of Water Containers and Aedes sp Larvae in Dengue-Endemic Areas of Tanjungpinang Riau," BKM Journal of Community Medicine and Public Health., vol. 37, no. 1, pp. 13-19, 2021, doi: 10.22146/bkm.57738.

[30] P. Haddawy et al., "Large Scale Detailed Mapping of Dengue Vector Breeding Sites Using Street View Images," Neglected Tropical Diseases, vol. 13, no. 7, pp. 1-12, 2019, doi: 10.1371/journal.pntd.0007555.

[31] D. Widiastuti, A. P. Kesuma, and N. Pramestuti, "Entomological Index and Transovarial Transmission Contribute To Dengue Haemorrhagic Fever Outbreaks in Banjarnegara Regency," Sp.irakel, vol. 8, no. 1, pp. 30-37, 2016, doi: 10.22435/spirakel.v8i1.6136.30-37.

[32] S. G. Purnama and T. Baskoro, "Maya Index and Larva Density Aedes aegypti toward Dengue Iinfection," Makara, vol. 16, no. 2, pp. 57-64, 2012, doi: 10.7454/msk.v16i2.1630.

[33] P. W. Dhewantara and A. Dinata, "the Maya Index Analysis on Dengue Patient Household in Banjar City, 2012," Balaba J. Litbang Pengendali. Penyakit Bersumber Binatang Banjarnegara, vol. 11, no. 1, pp. 1-8, 2015, doi: 10.22435/blb.v11i1.4148.1-8.

[34] N. E. Adams, "Bloom's Taxonomy of Cognitive Learning Objectives," Journal of the Medical Library Association, vol. 103, no. 3, pp. 152-153, 2015, doi: 10.3163/1536-5050.103.3.010.

[35] T. Marcinkowski and R. Alas, "Reviews of Research on the Attitude-Behaviour Relationship and Their Implications for Future Environmental Education Research," Environmental Education Research, vol. 25, no. 4, pp. 459-471, doi:10.1080/13504622.2019.1634237

[36] Md. I. Hossain et al., "Knowledge, Awareness and Preventive Practices of Dengue Outbreak in Bangladesh: A countrywide study," PLoS One, vol. 16, no. 6, pp. 1-17, 2021, doi:10.1371/journal.pone.0252852.

[37] A. M. Yusuf and N. A. Ibrahim, "Knowledge, Attitude and Practice towards Dengue Fever Prevention and Associated Factors among Public Health Sector Health-Care Professionals: In Dire Dawa, Eastern Ethiopia," Risk Management and Heatlhcare Policy, vol. 12, pp. 91-104, 2019, doi:10.2147/RMHP.S195214.

[38] M. Dhimal et al., "Knowledge, Attitude and Practice Regarding Dengue Fever among the Healthy Population of Highland and Lowland Communities in Central Nepal," PLOS ONE., vol. 9, no. 10, pp. 1-15, 2014. doi:10.1371/journal.pone.0110605.

[39] H. Fuadzy et al., "Risk factors associated with Dengue Incidence in Bandung, Indonesia: a Household based CaseControl Study," Health Science Journal of Indonesia, vol. 11, no. 1, pp. 45-51, 2020, doi: 10.22435/hsji.v11i1.3150. 
[40] A. Sethupathy, I. M. Sudarmaja, L. Ariwati, "The Level of Knowledge and Attitude towards Dengue Fever Among Medical Students of Udayana University, Bali, Indonesia in 2018," Intisari Sains Medis., vol. 10, no. 3, pp. 664670, 2019. doi: 10.15562/ism.v10i3.479.

[41] S. Phuanukoonnon, M. Brough, and J. H. Bryan, "Folk Knowledge about Dengue Mosquitoes and Contributions of Health Belief Model in Dengue Control Promotion in Northeast Thailand," Acta Trop., vol. 99, no. 1, pp. 6-14, 2006, doi: 10.1016/j.actatropica.2006.05.012.

[42] M. Mohamad, M. I. Selamat, and Z. Ismail, "Factors Associated with Larval Control Practices in a Dengue Outbreak Prone Area," J. Environ. Public Health, vol. 2014, id. 45917, doi: 10.1155/2014/459173.

[43] Y. Thavara et al., "Larval Occurrence, Oviposition Behavior and Biting Activity of Potential Mosquito Vectors of Dengue on Samui Island, Thailand," Vector Ecol., vol. 26, no. 2, pp. 172-180, 2001, doi: 10.1007/s13149-0110154-4.

[44] Ministry of Health of the Republic of Indonesia, "Regulation of the Minister of Health of The Republic of Indonesia Guidelines for Large-Scale Social Restrictions in the context of Accelerating Handling of Coronavirus Disease in 2019," [Online]. Available: Minister of Health Regulation, 2020, https://peraturan.bpk.go.id/Home/Details/135220/permenkes-no-9-tahun-2020.

[45] A. Fakhurozi, T.T. Suhariyanto, and M. Faishal, "Analysis of Environmental Impact and Municipal Waste Management Strategy: A Case of the Piyungan Landfill, Yogyakarta, Indonesia," Journal on Optimization of System at Industries, vol. 20, no. 1, pp. 61-71, 2021, doi: 10.250/josi.v20.n1.p61-71.2021.

[46] L. Salsabila, E. P. Purnomo, and H. D. Jovita, "The Importance of Public Participation in Sustainable Solid Waste Management," Journal of Governance and Public Policy, vol. 2, no. 2, pp. 106-123, 2021, doi: 10.18196/jgpp.v8i2.11519.

[47] Ministry of Health of the Republic of Indonesia, "Implementation of DHF Prevention and Control in the COVID19 Pandemic Situation," Directorate of Disease Prevention and Control, 2020, [Online]. Avilable: https://infeksiemerging.kemkes.go.id/download/SE_Pelaksanaan_Pencegahan_dan_Pengendalian_DBD_dalam_S ituasi_Pandemi_Covi-19.pdf.

[48] Ministry of Health of the Republic of Indonesia, "Guidelines for the Prevention and Control of Coronavirus Disease (COVID-19), Revision Five," Directorate General of Disease Control and Environmental Health, 2020, [Online]. Available: https://covid19.go.id/p/protokol/pedoman-pencegahan-dan-pengendalian-coronavirus-diseasecovid-19-revisi-ke-5.

[49] D. A. Marha, M. Z. Fatah, and W. Winarko, "The Role of Health Workers and Community Leaders to Prevent Dengue Hemorrhagic Fever in Magetan, East Java," J. PROMKES, vol. 8, no. 2, pp. 172-181, Sep. 2020, doi: 10.20473/jpk.v8.i2.2020.172-181.

[50] W. Damanik, N. Nurmaini, and K. Rochadi, "Effectiveness of Larva Monitoring Training on Knowledge of Dengue Hemorragic Fever Control among Primary School Students in Sibolga, North Sumatera," Epidemiology and Public Health, vol. 4, no. 3, pp. 183-188, 2019, doi: 10.26911/jepublichealth.2019.04.03.05.

[51] R. C. Pradana, R. Dharmawan, and E. S. Sulaeman, "The Effectiveness of Mosquito Breeding Site Eradication and Role of Wiggler Controller toward Countermeasure Effort of Dengue Hemorrhagic Fever in Klaten, Central Java," J. Epidemiol. Public Heal., vol. 1, no. 1, pp. 37-48, 2016, doi: 10.26911/jepublichealth.2016.01.01.05.

[52] F. D. A. Suryanegara, S. Suparmi, and N. Setyaningrum, "The Description of Larva Free Index as COMBI (Communication for Behavioural Impact) Dengue Haemorrhagic Fever Prevention Indicator," KESMAS, vol. 13, no. 3, pp. 338-344, 2018, doi: 10.15294/kemas.v13i3.5844.

[53] F. Rabbani, L. Shipton, W. Aftab, K. Sangrasi, S. Perveen, and A. Zahidie, "Inspiring health worker motivation with supportive supervision: a survey of lady health supervisor motivating factors in rural Pakistan," BMC Health Service Research, vol. 16, no. 397, pp. 494-500, 2016, doi: 10.1186/s12913-016-1641-x.

[54] D. Delta and T. Djafar, "Movement Of Healthy Society Living-Anti Dengue Hemorrhagic Fever In Sumarambu Village, Telluwanua District, Palopo City," RESONA, vol. 4, no. 2, pp. 82-95, 2020, doi: 10.35906/resona.v4i2.553.

[55] Ministry of Health of the Republic of Indonesia, "Towards New Normal," Directorate of Health Promotion and Community Empowerment, 2020, [Online]. Available: https://promkes.kemkes.go.id/menuju-adaptasi-kebiasaanbaru.

[56] National Disaster Relief Agency of Yogyakarta, "Limitation of Micro-Based Community Activities in DIY to Control the Spread of Corona Virus Disease 2019 (COVID-19)," Disaster Management Operations Control Center, 2020, [Online]. Available: http://bpbd.jogjaprov.go.id/dasar-hukum.

[57] N. A. Pascawati and T. B. T. Satoto, "Public Knowledge, Attitudes and Practices towards COVID-19," International Journal Public Health Science (IJPHS), vol. 9, no. 4, pp. 292-302, 2020, doi: 10.11591/ijphs.v9i4.20539.

[58] Ministry of Health of Indonesia, "Guidelines for Community Empowerment in COVID-19 in Neighbourhood/Hamlet/Village," Directorate of Health Promotion and Community Empowerment, 2020, [Online]. Available: https://covid19.kemkes.go.id/protokol-covid-19/pedoman-pemberdayaan-masyarakat-dalampencegahan-covid-19-di-rt-rw-desa/.

[59] F. D. Astuti and A. Susanti, "Difference in Entomology Index for Adult larva Monitor and Child Larva Monitor in Mejing Kidul Hamlet, Ambarketawang, Gamping, Sleman, Yogyakarta," J. Vektor Penyakit, vol. 11, no. 1, pp. 3342, 2017, doi: 10.22435/vektorp.v11i1.6488.33-42.

[60] Asian Pacifik Observatory on Health System and Policies, "The Republic of Indonesia Health System Review," Health System in Transition, vol. 7, no. 1, 2016. 